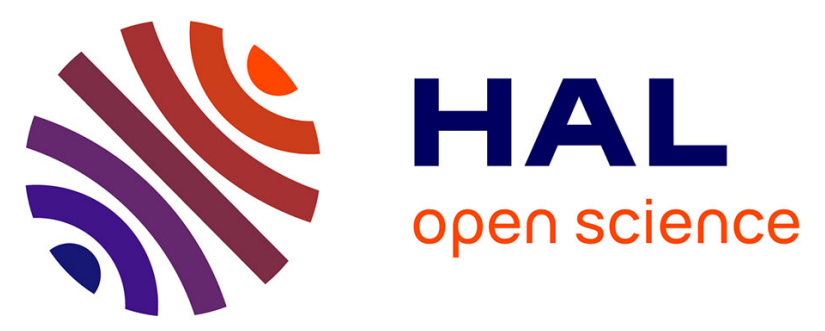

\title{
Using Confidence Factor to Improve Reliability of Wide Frequency Range Impedance Measurement. Application to H.F. Transformer Characterization
}

Abdelhadi Besri, Hervé Chazal, Jean-Pierre Kéradec, Xavier Margueron

\section{To cite this version:}

Abdelhadi Besri, Hervé Chazal, Jean-Pierre Kéradec, Xavier Margueron. Using Confidence Factor to Improve Reliability of Wide Frequency Range Impedance Measurement. Application to H.F. Transformer Characterization. IEEE Instrumentation \& Measurement Technology Conference, May 2009, Singapour, Singapore. 10.1109/IMTC.2009.5168424 · hal-00385349

\author{
HAL Id: hal-00385349 \\ https://hal.science/hal-00385349
}

Submitted on 19 May 2009

HAL is a multi-disciplinary open access archive for the deposit and dissemination of scientific research documents, whether they are published or not. The documents may come from teaching and research institutions in France or abroad, or from public or private research centers.
L'archive ouverte pluridisciplinaire HAL, est destinée au dépôt et à la diffusion de documents scientifiques de niveau recherche, publiés ou non, émanant des établissements d'enseignement et de recherche français ou étrangers, des laboratoires publics ou privés. 


\section{Using Confidence Factor to Improve Reliability of Wide Frequency Range Impedance Measurement. Application to H.F. Transformer Characterization}

\author{
A. Besri, H. Chazal, J-P. Keradec, senior member IEEE \\ Laboratoire de Génie Electrique de Grenoble (G2Elab), UMR \\ 5269 INPG-UJF-CNRS \\ 38402 Saint Martin d'Hères Cedex, France \\ besri@g2elab.grenoble-inp.fr
}

\begin{abstract}
Impedance analyzers are efficient in acquiring wide range impedance measurements in a wide frequency range. However, when measuring low impedances, short circuits used for compensation process can't be considered as ideal and analogue problem appears for open circuit compensation. Fortunately, because impedance matrix of a two-port passive circuit is symmetrical, characterizing this circuit by four independent impedance measurements introduces redundancy. That property supplies a useful consistency test we call "confidence factor". Looking at this factor, several causes of measurement inaccuracy can be detected. Alternatively, extra equation supplied by redundancy can also be used to add one unknown impedance to the three computed. This way, impact of the impedance of a real imperfect short-circuit can be removed. In this paper, we first present the interest of the confidence factor and then we show how to lower errors related to imperfect shortcircuit. Finally, we show how to use these advances to better characterize HF power transformers and to measure weak wiring inductances.
\end{abstract}

Keywords-component; H.F. power transformers, impedance measurements, confidence factor.

\section{MEASUREMENT INTEREST AND CHOICE OF APPARATUS}

\section{A. Impedance and frequency range values}

Because of their quite linear behaviour, passive components used in power electronics (i.e. transformers, inductors and capacitors) are characterized mostly by impedances measured in a wide frequency range. To run reliable circuit simulations, component behaviours must be known from d.c. to several $\mathrm{MHz}$ because, in power electronics, waveforms have high harmonic content.

Measured impedances are sometimes very small (less than $10 \mathrm{~m} \Omega$ or $100 \mathrm{nH}$ ), and sometimes very high (less than $10 \mathrm{pF}$ ). For example, during transformer characterization, such values appear during measurements of, respectively, short circuited and open impedances.

\section{B. Apparatus chosen for measurement}

Various methods have been developed for measuring impedances accurately. They all have advantages and drawbacks [1], [2]. Choice between these different techniques is based on frequency range, magnitude of impedance to
X. Margueron

Laboratoire d'Electrotechnique et d'Electronique de Puissance (L2EP), Ecole Centrale de Lille - Cité Scientifique BP 48 - 59851 Villeneuve d'Ascq Cedex - France

measure, desired accuracy and, also, simplicity of use. According to these criterions, apparatus that best suited to these measurements appeared to be an impedance analyzer. It is why we choose Agilent 4294A impedance analyzer. This apparatus uses 4-points measurement method into an auto-balanced bridge circuit [3]

This paper mainly aims at improving the accuracy of impedance measurements characterizing a n-ports linear passive device such as n-winding HF power transformers. To reach this target, confidence factor is introduced in section II and some of the causes of inaccuracy it helps to detect are presented in this section. Then, in section III, we discuss about the limits of usual compensations and we show how to cancel the impact of an imperfect short-circuit on measurements acquired to characterize n-port linear passive circuits. Impedance measurements acquired on a three winding HF transformer are presented in section IV. These measurements give the opportunity to present special adequate precautions, to check the benefit of confidence factor and to try the cancellation of the impact of short circuit impedance.

\section{BENEFIT OF CONFIDENCE FACTOR}

\section{A. Introducing the confidence factor}

Symmetry of impedance matrix attached to every passive two port component results in relation (1) that links short $Z_{s}$ and open $Z_{o}$ impedances seen from both sides of the circuit.

$$
Z_{s} Z_{o}^{\prime}=Z_{s}^{\prime} Z_{o}
$$

Prime indicates impedances seen from the second port. We call "confidence factor" the modulus $C F$ of the ratio of the two members of (1).

$$
C F=\left|\frac{Z_{o} Z_{s}^{\prime}}{Z_{o}^{\prime} Z_{s}}\right|
$$

This factor, which is not linked to a special representation of the circuit, is normally equal to 1 whatever the frequency is so any deviation from this value must attract attention. Some examples of common causes that cause deviation of $\mathrm{CF}$ are listed below.

First of them, non-linearity due to an inadequate excitation level can disturb one measurement. This kind of non-linearity 
is mostly due to magnetic material behaviour. In such a case, measurements must be taken again after changing oscillator level. As soon as oscillator level keeps the component in its linear region, CF comes back close to 1 . A fast computation of the order of magnitude of core induction can confirm the origin of the problem. When characterizing a transformer, this problem mainly occurs during open circuit impedance measurement, in the low frequency side. Use of confidence factor greatly eases the detection of this measurement problem.

Another cause of deviation is related to open-circuit and short-circuit impedance that are not ideal and should not be considered as infinite or null impedance. Mentioned impedance can be either that introduced for wiring compensation or that used to load the two port component. After any no-linearity has been eliminated, if confidence factor is not close to one, we compare measured impedance values to the resolution limits of our apparatus. According to our experience, we locate these limits, for the upper one to that given by the impedance of a $1 \mathrm{pF}$ capacitance and for the lower one, to that of a $10 \mathrm{nH}$ inductance. Generally, at frequency where confidence factor is far from 1 , at least one among the four involved impedances is close to the resolution limit. This gives interesting information regarding measurement to acquire again and special care to do this. Practical example is given in section IV.

To end, let us mention another cause of inaccuracy. To obtain accurate values, measurements always include a compensation step which aims at removing wiring impact. Calculation carried out for this correction supposes that null and infinite impedances are available and we told above that is not always true. Same calculation assumes also there is no coupling (neither inductive nor capacitive) between load and component terminals: impedances simply add together. In some cases, this assumption is difficult to justify!

To sum up, looking at confidence factors while characterizing several-ports linear passive circuits gives useful information regarding consistency of measurements and it helps to find guilty measurements.

\section{LIMITS OF USUAL COMPENSATIONS}

\section{A. Wiring compensation}

Generally speaking, device under test (DUT) is connected to measuring apparatus through a passive two ports circuit which includes: test fixture, pair of wires,.... So, when DUT impedance is connected as the load impedance of this circuit, measured impedance is its input impedance which is slightly different. An example is given in figure 1 in which the DUT is a transformer.

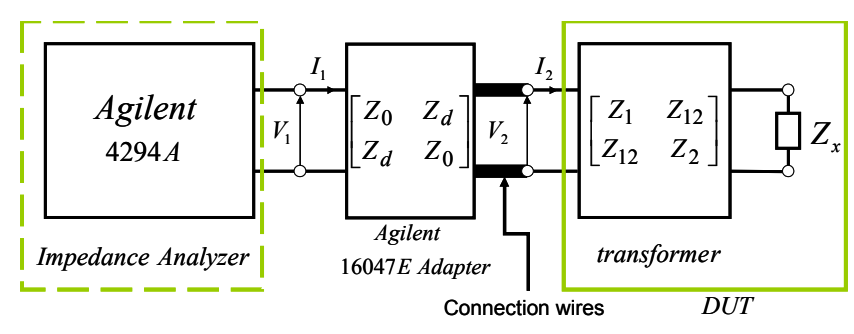

Figure 1. Agilent adapter and specific fixture scheme
To characterize and, then, compensate the adapter with the entire wiring circuit, compensation measurements are recommended. As soon as this linking device is characterized, searched impedance can be deduced from measured one.

Series impedance of that two port circuit is generally far smaller than its parallel impedance. For this reason, locating series impedance before or after parallel impedance doesn't matter so its equivalent circuit can be considered symmetrical. For that reason, it can be characterized by only two impedances and that justifies "open-short" compensation process which is described below.

Let " $\mathrm{m}$ " denote the acquired measurement, " $o$ " the opencircuit impedance and " $s$ " the short-circuit impedance. Two measurements are performed (open-circuit and short-circuit measurements, respectively $Z_{o m}$ and $Z_{s m}$ ), in order to characterize the impedance matrix of the adapter.

$$
Z_{\text {om }}=Z_{o} ; \quad Z_{s m}=Z_{o}-\frac{Z_{d}^{2}}{Z_{o}}
$$

Knowing $Z_{o}$ and $Z_{s m}, Z_{d}$ (figure 1 ) is easily deduced from (3). Then, it is simple to deduce DUT impedance $Z_{x}$ from measured impedance $Z_{x m}(4)$ :

$$
Z_{x}=Z_{x m} \frac{1-\left(Z_{s m} / Z_{x m}\right)}{1-\left(Z_{x m} / Z_{o m}\right)}
$$

Value given by the analyzer after "open-short" compensation process is computed this way.

Refined characterization of wiring device is possible using the "open-short-load compensation". This process requires a third compensation measurement, acquired with a finite load. Owing to this, the two port device is characterized as a general, non-symmetrical device. To be effective, used load must have an impedance value of the same order of magnitude as that to measure and, above all, this impedance must be perfectly known. These two conditions are difficult to gather for our components.

\section{B. Limits of "open-short" compensation}

To simplify, action of open-short compensation is to remove impedance seen during short circuit compensation from that seen during the measurement and to subtract admittance acquired during open circuit compensation from that measured. Thinking to this, a first precaution arises. The whole connecting device must stay unchanged between compensations and impedance measurements. For example, separate wires with variable shape must be avoided: with such a wiring, impedance added during impedance measurement could be different from that seen during short-circuit compensation so subtraction does not eliminate its effect. Disconnections which can modify contact impedances are also harmful.

Second remark regarding accuracy is that, because obtained impedance value results from differences, it is recommended to subtract values as different as possible. So series impedance of

This work is supported by

THALES AIRBORNE SYSTEMS - Brest, FRANCE 
wiring device must remains as weak as possible and so it is for its parallel admittance.

As long as open circuit impedance remains far higher than short-circuit one, "open-short" compensation is mathematically well established. However, a careful look to its principle shows it relies on the constancy of wiring impedances (from compensation step to measuring step) and on perfection of open and short impedances used for compensation. Unfortunately, perfection is never reached and residual errors remain, mainly when DUT impedance is either as high as open-circuit one or as low as short-circuit one. In the following, we will present precautions that result from these observations.

\section{Correction of non-zero short-circuit impedance}

Before presenting experimental examples, let us show how it is possible to remove entirely the impact of the non-zero impedance of a short-circuit measurement.

During the characterization of a two winding transformer, if a winding, let say the secondary, is a low voltage one, impedance measured between its terminals is low, especially if primary is shorted, so it is difficult to measure. Weak impedance of the short circuit used to load the secondary disturbs both short-circuit impedance seen from primary side and short-circuit compensation measured from the secondary side. Therefore, two among the four measurable impedances being impacted, no accurate characterization can be expected.

To overcome this problem, we use the same wire to shortcircuit the secondary during measurements acquired from the primary side than that used for short circuit compensation on the secondary side. In practice, to keep its impedance constant, this wire is not disconnected between the two measurements. If all other impedances involved look ideal, the four impedances that appear in (1) supply four equations to determine the three independent parameters of our transformer and the short-circuit impedance.

Let us denote $Z_{w}$ the impedance of the short-circuit wire. Adding an " $\mathrm{m}$ " index to impedances directly measured and assuming that the short-circuit compensation is acquired when the primary is shorted, we get 4 equations to find 4 independent impedances: $Z_{o}, Z_{o}, Z_{s}$ and $Z_{w}$

$$
\begin{aligned}
& Z_{\text {om }}=Z_{o} \\
& Z_{s m}=Z_{o}-\frac{Z_{12}^{2}}{Z_{o}^{\prime}+Z_{w}} \text { where } Z_{12}^{2}=\left(Z_{o}^{\prime}-Z_{s}^{\prime}\right) Z_{o} \\
& Z_{s m}^{\prime}=Z_{s}^{\prime}-\frac{Z_{s}^{\prime} Z_{w}}{Z_{s}^{\prime}+Z_{w}} \\
& Z_{o m}^{\prime}=Z_{o}^{\prime}-\frac{Z_{s}^{\prime} Z_{w}}{Z_{s}^{\prime}+Z_{w}}
\end{aligned}
$$

Obviously, when $Z_{w}=0$, these equations shows that measured values equal theoretical ones. Solution of this set of equations is expressed in terms of $x$, defined below, which equals 1 when $Z_{w}=0$.

$$
\begin{aligned}
& x= \pm \sqrt{\frac{Z_{s m}}{Z_{s m}^{\prime}} \frac{Z_{o m}^{\prime}-Z_{s m}^{\prime}}{Z_{o m}-Z_{s m}}} \\
& Z_{o}=Z_{o m} \\
& Z_{s}=\frac{Z_{o m} Z_{s m}^{\prime} x}{Z_{o m}^{\prime}+Z_{s m}^{\prime}(x-1)} \\
& Z_{o}^{\prime}=Z_{o m}^{\prime}+Z_{s m}^{\prime}(x-1) \\
& Z_{s}^{\prime}=Z_{s m}^{\prime} x \\
& Z_{w}=Z_{s m}^{\prime} \cdot x \cdot(x-1)
\end{aligned}
$$

Despite mathematically both signs are acceptable for $x$, only one suits for equation (13). Indeed, value given by (13) is an impedance which can be measured on a passive circuit: its real part is necessarily positive. Generally, sign + in (9) suits to insure this property but let us underline that, in every case, values given by (10) to (14) are unique.

In order to verify the previous relations, we took the simple equivalent circuit of a known transformer, represented as established in [4], and shown in figure 2, and we computed the impedances that should have been measured with a given imperfect short-circuit. We did so, of course, to avoid experimental noise.

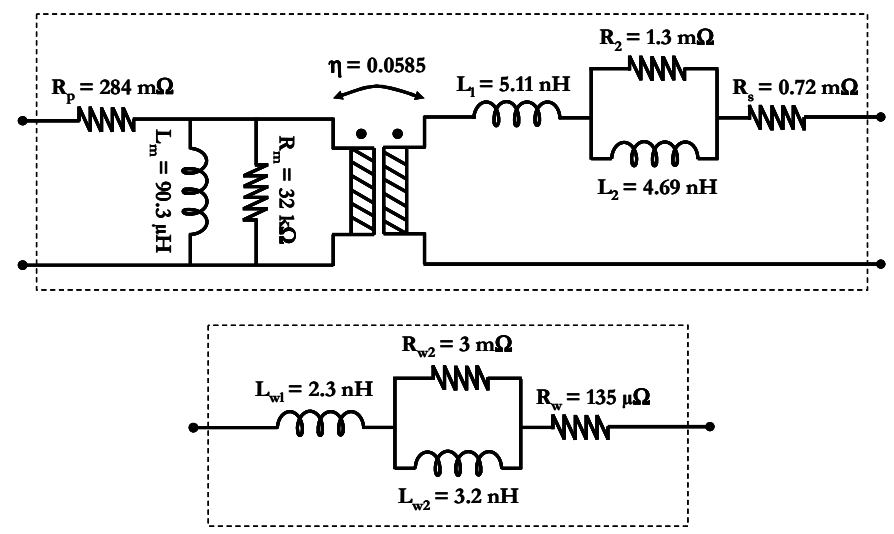

Figure 2. Electrical equivalent circuits of a two-winding transformer and of the short-circuit used for measurements

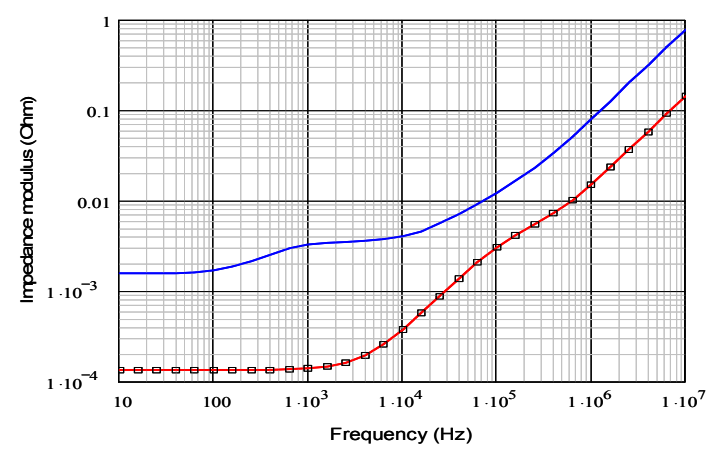

Figure 3. values found for Zw for both signs of $x$ "plus" (red curve) and "minus" (blue curve) compared to direct calculation ( square dots)

Then, we applied relations (9) to (13) to simulated measurements and we compared obtained impedances to those directly deduced from transformer circuit alone. This 
comparison has been done successively for both signs of $x$. Figure 3 shows the result for $Z_{w}$. Clearly, sign + chosen for (9) is the right one.

Before working with real measurements, it is interesting to have a look to the confidence factor we can be deduced from the previous simulated measurements (Figure 4). Despite shortcircuit used is very good, its impact appears clearly and, in practice, this warning suggests to apply the correction exposed above. Of course, to really improve measurement accuracy, numerous practical precautions will be taken. We describe this below, in detail.

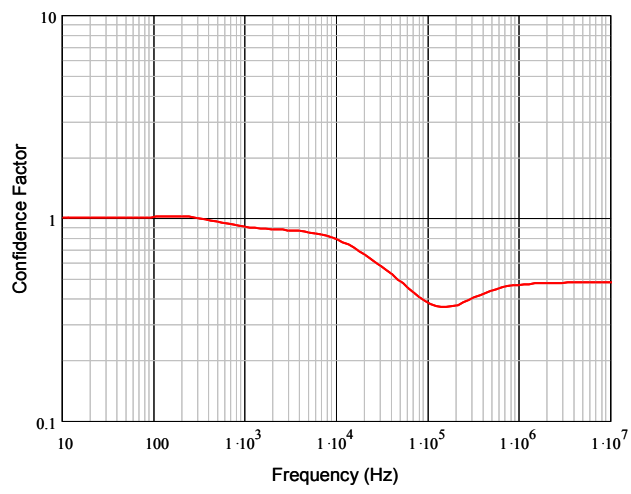

Figure 4. Confidence factor deduced from simulated measurement

\section{CHARACTERIZING A THREE WINDING TRANSFORMER}

\section{A. Component description and special care}

Recently, we characterized a $250 \mathrm{~W}$ three winding transformer designed to work at $125 \mathrm{kHz}$. We call its windings respectively: primary, secondary and auxiliary. Its secondary was sized for low voltage $(5 \mathrm{~V})$ applications so it showed low impedances, difficult to measure. Our characterization process has been already presented $[3,4,5,6]$.

All impedances needed for a full magnetic characterization where acquired using test fixture Agilent $16047 \mathrm{E}$ and we took special care to properly cancel wiring impact, using open-short compensations. Configuration of the analyzer was chosen as shown in TABLE I.

TABLE I. MEASUREMENT CONDITIONS

\begin{tabular}{|l|l|}
\hline Measure parameter : & IMPEDANCE MAG PHASE \\
\hline Adapter : & NONE \\
\hline Sweep type : & LOG \\
\hline Number of points : & 801 \\
\hline OSC level : & $100 \mathrm{mV}$ \\
\hline DC Bias : & OFF \\
\hline Bandwidth (BW) & 3 \\
\hline Sweep averaging : & OFF \\
\hline Point averaging : & 16 \\
\hline
\end{tabular}

Oscillator level was decreased to avoid non linearity behaviour in the low frequency side and fixed to $100 \mathrm{mV}$. Frequency resolution was adjusted to obtain resonance frequencies with enough accuracy. This last point matters for the determination of parallel capacitances.

Using Agilent 4194A, short circuit compensation must be acquired before the measurement itself. With that in mind, we acquire the 12 needed measures in a specific order shown in Table 2. This order aims to avoid disconnections each time it is possible. Moreover, short-circuit used for the compensation of impedances seen from secondary side is the same as that used to load the secondary.

TABLE II. MEASUREMENT PROTOCOL

\begin{tabular}{|c|c|c|c|}
\hline \multirow{2}{*}{$\begin{array}{c}\text { Port } \\
\text { number }\end{array}$} & \multicolumn{3}{|c|}{ Table of measurement protocol } \\
\hline & $\begin{array}{l}\text { Short-circuit } \\
\text { compensation }\end{array}$ & Impedance measurements & \\
\hline \multirow{4}{*}{1} & \multirow{4}{*}{$\mathrm{Z}_{1 \mathrm{~s} \_2 \mathrm{o} \_3 \mathrm{o}}$} & $Z_{1 \_20 \_3 o}$ & $\mathrm{~m} 1$ \\
\hline & & $\mathrm{Z}_{1 \_2 \mathrm{o} \_3 \mathrm{~s}}$ & $\mathrm{~m} 5$ \\
\hline & & $Z_{1 \_2 s \_3 s}$ & $\mathrm{~m} 10$ \\
\hline & & $\mathrm{Z}_{1-2 \mathrm{~s} \_3 \mathrm{o}}$ & $\mathrm{m} 4$ \\
\hline \multirow{2}{*}{3} & \multirow{2}{*}{$Z_{3 s \_10 \_2 s}$} & $\mathrm{Z}_{3 \_1 \mathrm{o} \_2 \mathrm{~s}}$ & $\mathrm{~m} 9$ \\
\hline & & $\mathrm{Z}_{3 \_1 \mathrm{~s} \_2 \mathrm{~s}}$ & $\mathrm{~m} 12$ \\
\hline \multirow{4}{*}{2} & \multirow{4}{*}{$\mathrm{Z}_{2 \mathrm{~s} \_1 \mathrm{~s} \_3 \mathrm{o}}$} & $Z_{2 \_1 s \_30}$ & $\mathrm{~m} 6$ \\
\hline & & $\mathrm{Z}_{2 \_1 \mathrm{~s} \_3 \mathrm{~s}}$ & $\mathrm{~m} 11$ \\
\hline & & $\mathrm{Z}_{2 \_1 \mathrm{o} \_3 \mathrm{~s}}$ & $\mathrm{~m} 7$ \\
\hline & & $Z_{2 \_10 \_30}$ & $\mathrm{~m} 2$ \\
\hline \multirow{2}{*}{3} & \multirow{2}{*}{$Z_{3 s_{-} 10 \_2 o}$} & $Z_{3 \_10 \_20}$ & $\mathrm{~m} 3$ \\
\hline & & $Z_{3 \_1 s \_20}$ & $\mathrm{~m} 8$ \\
\hline
\end{tabular}

B. Example of experimental results and accuracy estimation

The four impedances seen from primary and secondary side in open circuit and short-circuit operating conditions are shown in figure 5.

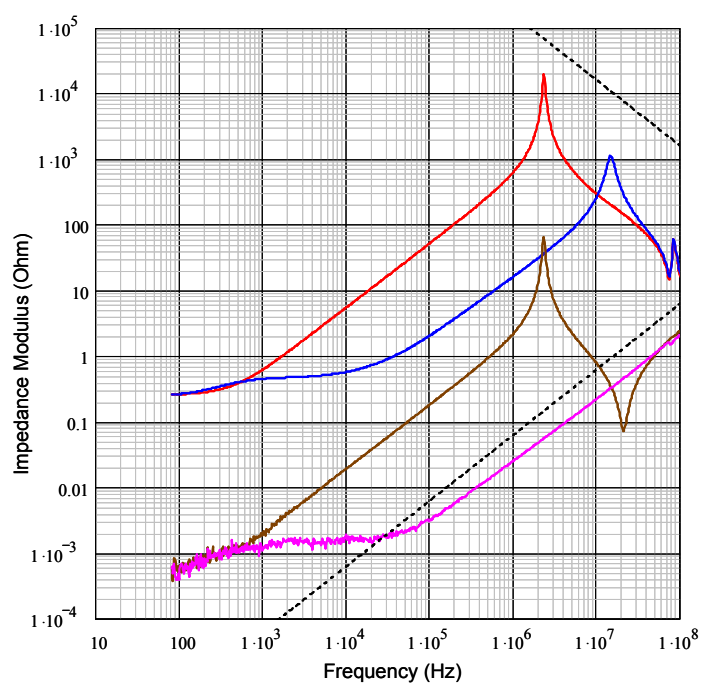

Figure 5. Impedance measurements seen from primary (upper curves) and secondary side in open circuit and short-circuit operating conditions. 
The two doted lines correspond respectively to impedances of a $10 \mathrm{nH}$ inductor and a $1 \mathrm{pF}$ capacitor. They give a rough idea of resolution limits of our equipment. In most cases, when confidence factor moves away from 1, one among the four involved impedances is close to one of these limits.

As supposed during the component description, impedances measured from the secondary side are very low and one of them remains below the lower limit of resolution of our apparatus above $30 \mathrm{kHz}$. Plotting confidence factor bring the confirmation that a serious problem of accuracy arises above this frequency: $C F=0.45$ !

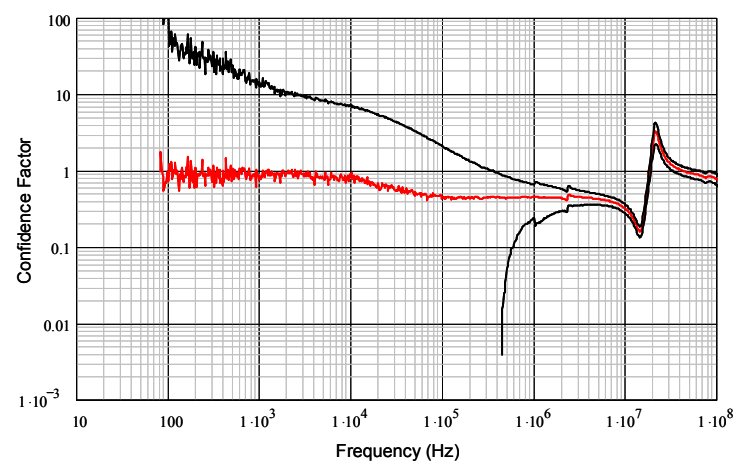

Figure 6. Confidence factor of primary secondary transformer: in red direct computation, in black, upper and lower limits deduced from uncertainty.

At this point, it is interesting to look at our results with the light of the uncertainty evaluation given by Agilent. Applying formulas supplied by Agilent [7], relative uncertainty on each measured impedance is estimated and that on $C F$ is deduced directly. Black curves shown in figure 6 are upper and lower limits which result from this evaluation.

We first observe that, between $400 \mathrm{kHz}$ and $7 \mathrm{MHz}$, deviation from 1 of $C F$ is not due to uncertainty: an other cause, not taken into account in Agilent calculation, must be invoked. We suppose it to be the impedance of the short circuit used on the secondary side. Second, our measurements seem more accurate than Agilent estimation let us suppose. While, according to Agilent estimation, $C F$ could reach more than 10 or less than $10^{-3}$ below $10 \mathrm{kHz}$, it is, in fact, surprisingly close to 1 . This is due, at least partly, to the precautions we take to avoid repeatability errors on open and short-circuit compensation measurements. These errors are, probably, estimated prudently by Agilent. On the other hand, we observe that none among the errors the confidence factor helps to detect are mentioned in the calculation proposed by Agilent.

While $C F=1$ does not prove our measurements are accurate (a standard weak impedance should be required to do this), at least, this indicates they are consistent together.

Now, we want to check impact cancellation of the imperfect short-circuit connected to the secondary. No verification is possible if tested circuit owns only 2 ports because, as we use the equality $C F=1$ to solve equation set, corrected impedances always verify this equality. On the opposite, if more than 2 ports are accessible, such a verification is possible. Below, we show that for our three winding transformer.

\section{Characterizing the three winding transformer}

To characterize the magnetic part of our transformer, we acquired the 12 impedances which appear in table 2 . In this component, we can find three 2-winding transformers when the third winding is open and three others when the third winding is shorted. According to this, six confidence factors can be calculated. We often plot the first three.

In order to check our cancellation of the short circuit impedance, we proceed in to steps. First, we use impedances shown in figure 5 to evaluate $Z_{w}$ (14). Result is shown in figure 7 in which the blue curve is given by equivalent circuit shown in figure 2. Calculated values being one too noisy, especially in the low frequency side, in the following, we use this approximation.

For short-circuit calculated impedance, serial resistor, averaged between 1 and $10 \mathrm{kHz}$, equals to $135 \mu \Omega$. The inductance, well seen between $10 \mathrm{kHz}$ and $10 \mathrm{MHz}$, decreases from $5,5 \mathrm{nH}$ at $10 \mathrm{kHz}$ to $2,3 \mathrm{nH}$ at $10 \mathrm{MHz}$ and, in the same time, above $10 \mathrm{kHz}$, serial resistance is proportional to frequency at power one half, that is consistent with eddy current effects. All these points are accurately modelled by equivalent circuit shown in figure 2 . Let us remark also that all these orders of magnitude are compatible with the nature and the size of used wire: $13 \mathrm{~mm}$ of copper wire, $1.78 \mathrm{~mm}$ diameter. To sum up, this estimation is consistent with physical properties of the wire.

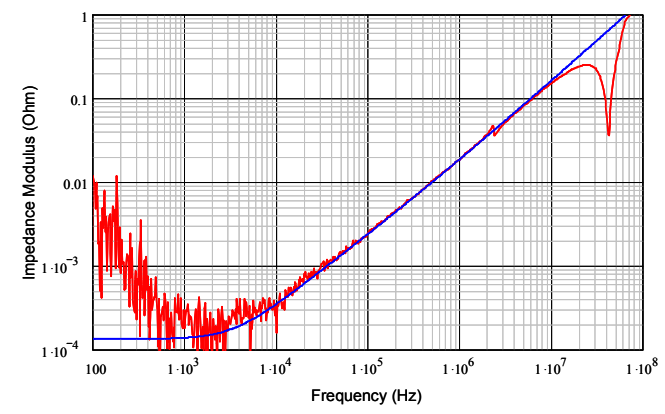

Figure 7. Impedance of short-circuit used at secondary side.

Then, we look at the auxiliary secondary transformer (primary open). Above $30 \mathrm{kHz}$, its confidence factor deviates from 1 (figure 8) and we suppose that this is due to the same non ideal short-circuit. Knowing corrected values found for primary-secondary transformer, we know all about impedance of secondary short-circuit and about impedance subtracted for short circuit compensation. So we can correct three impedances which characterize auxiliary-secondary transformer, forth one needs no correction. This is done, as follows, using impedance names introduced in table 2.

Referring to table 2, imperfect compensation $\Delta Z$ used during measurements seen from the secondary is the same as that used previously for $\mathrm{m} 6$. So the two corresponding impedances measured on auxiliary-secondary transformer are corrected simply (15 and (16).

$$
\mathrm{m} 7=\mathrm{m} 7_{\mathrm{m}}+\Delta Z \text { and } \mathrm{m} 2=\mathrm{m} 2_{\mathrm{m}}+\Delta Z
$$


with: $\Delta Z=\mathrm{m} 6 / / Z_{w}$

where $\mathrm{m} 6$ is the new name of $Z_{\mathrm{s}}^{\prime}$ given by (13)

For impedances seen from the auxiliary side, one (m3) needs no correction. To end, $\mathrm{m} 9$ must be corrected because, during this measurement, the load was not null as expected. To derive the necessary relation, we write measured $\left(\mathrm{m} 9_{\mathrm{m}}\right)$ and real (m9) values of impedance $m 9$ using mutual impedance $\mathrm{Zm}$.

$$
\mathrm{m} 9_{m}=\mathrm{m} 3-\frac{\mathrm{Zm}^{2}}{\mathrm{~m} 3+\mathrm{ZW}} \quad \mathrm{m} 9=\mathrm{m} 3-\frac{\mathrm{Zm}^{2}}{\mathrm{~m} 3}
$$

Then we extract $\mathrm{Zm}^{2}$ from the two expressions. This finally leads to:

$$
\mathrm{m} 9=\mathrm{m} 9_{m}+\mathrm{Zw} \frac{\mathrm{m} 9_{\mathrm{m}}-\mathrm{m} 3_{\mathrm{m}}}{\mathrm{m} 2_{\mathrm{m}}+\Delta Z}
$$

According to these corrections, $\mathrm{m} 9$ and $\mathrm{m} 7$ values change by $40 \%$. Now, we can compare confidence factors obtained for auxiliary-secondary transformer before and after the correction. As seen in figure 8, improvement is spectacular.
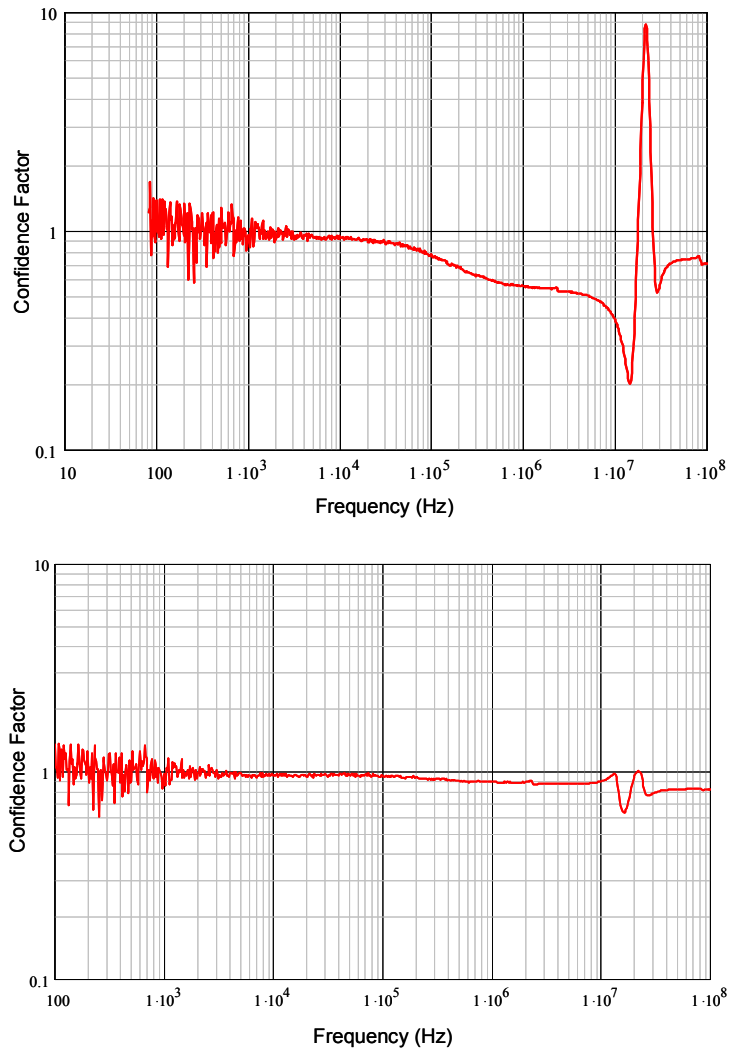

Figure 8. Confidence factor of auxiliary-secondary coupling. a) without and b) with correction of the short-circuit impedance.

Confidence factor also give us an order of magnitude of the capacitance resolution of our measurements. In the high frequency side, impedances show resonance frequencies. Because stray capacitance slightly varies when disconnecting, some of these resonances are shifted that leads to some inconsistencies. When this occurs, confidence factor shows sharp double peak deviation from 1. If measurement has been carried out carefully, adding or subtracting a small capacitor ( $1 \mathrm{pF}$ or less) in parallel with the highest impedance generally suffices to draw the curve closer to 1. So during this characterization, we can say that capacitance resolution was about $1 \mathrm{pF}$.

\section{IMPEDANCE MAGNIFICATION}

It is well know that impedance seen from primary side of a transformer can be much higher (if its voltage ration is less than 1) than that connected as a load of its secondary side. We used this property to measure small wiring inductances (some $\mathrm{nH}$ ) with a quite good sensitivity. Of course, this method is efficient only for frequencies located inside the bandwidth of the transformer, where coupling is strong. During this experiment, we took advantage of a fine characterization of the transformer, carried out as depicted above.

\section{CONCLUSION}

Despite impedance analyzer is an efficient tool measure impedances, when impedances approach $1 \mathrm{pF}$ or $10 \mathrm{nH}$, some cause of inaccuracy can no longer be neglected. We often face to these problems during $\mathrm{HF}$ power transformers characterization. For devices which owns more than two ports, confidence factor introduced in this paper supplies a convenient warning to know if these effects are negligible or not.

In addition, the redundancy we brought in light about $\mathrm{n}$ port linear devices allows some stray effects, such as non-zero impedance of a short circuit, to be cancelled. Joined to experimental precaution we presented, these corrections lead to reach accuracy far better than claimed by the manufacturer of the analyzer. These methods also lead us to evaluate the resolution limits for inductances and capacitances

\section{REFERENCES}

[1] Impedance Measurement Handbook, Agilent, 17 Dec. 2003, ref 5950-3000.

[2] 8 Hints for Successful Impedance Measurements, Agilent, Application Note 346-4 06/00.

[3] X. Margueron, "Elaboration, sans prototypage, du circuit équivalent d'un transformateur planar" Thèse de l'Université Joseph Fourier, G2ELab, Grenoble, 31 Octobre 2006.

[4] X. Margueron, J. P. Keradec, "Identifying the magnetic part of the equivalent circuit of n-winding transformer", IEEE Transactions on Instrumentation and Measurements, Feb. 2007, vol. 56, no. 1, pp. 146152.

[5] X. Margueron, J. P. Keradec, "Design of equivalent circuits and characterization strategy for n-input coupled inductors", IEEE Transactions on Industry Applications, Jan.-Feb. 2007, vol. 43, no. 1, pp. 14-22.

[6] J. P. Keradec, "Transformateurs HF à n enroulements. Circuits à constantes localisées ", dossier D 3058 Fev 2008 and "Transformateurs $\mathrm{HF}$ à n enroulements. Identification expérimentale", dossier D 3059 , Mars 2009, Les Techniques de l'Ingénieur, Paris (F). http://www.techniques-ingenieur.fr/recherche/ResultList.asp

[7] 4294A Precision Impedance Analyzer, Operation manual, Agilent, 15 Dec. 2000, pp 323-354 